Philip Ruff, Mercedes Carrillo-Solano, Nils Ulrich, Andrea Hadley, Patrick Kluth, Maria Eugenia Toimil-Molares*, Christina Trautmann and Christian Hess*

\title{
Nanoscale Structuring in Confined Geometries using Atomic Layer Deposition: Conformal Coating and Nanocavity Formation
}

https://doi.org/10.1515/zpch-2017-1058

Received October 17, 2017; accepted January 18, 2018

Abstract: Nanoscale structuring in confined geometries using atomic layer deposition (ALD) is demonstrated for surfaces of nanochannels in track-etched polymer membranes and in mesoporous silica (SBA-15). Suitable process conditions for conformal ALD coating of polymer membranes and SBA-15 with inorganic oxides $\left(\mathrm{SiO}_{2}, \mathrm{TiO}_{2}, \mathrm{Al}_{2} \mathrm{O}_{3}\right)$ were developed. On the basis of the oxidecoated layers, nanochannels were further structured by a molecular-templated ALD approach, where calixarene macromolecules are covalently attached to the surface and then embedded into an $\mathrm{Al}_{2} \mathrm{O}_{3}$ layer. The removal of calixarene by ozone treatment results in 1-2 nm wide surface nanocavities. Surfaces exposed to different process steps are analyzed by small angle X-ray scattering (SAXS) as well as by X-ray photoelectron and infrared spectroscopy. The proposed nanostructuring process increases the overall surface area, allows controlling the hydrophilicity of the channel surface, and is of interest for studying water and ion transport in confinement.

\footnotetext{
*Corresponding authors: Maria Eugenia Toimil-Molares, Materials Research Department, GSI Helmholtzzentrum, Planckstr.1, 64291 Darmstadt, Germany, e-mail: M.E.ToimilMolares@gsi.de; and Christian Hess, Eduard-Zintl-Institut für Anorganische und Physikalische Chemie, Technische Universität Darmstadt, Alarich-Weiss-Str. 8, 64287 Darmstadt, Germany, e-mail: hess@pc.chemie.tu-darmstadt.de

Philip Ruff: Eduard-Zintl-Institut für Anorganische und Physikalische Chemie, Technische Universität Darmstadt, Alarich-Weiss-Str. 8, 64287 Darmstadt, Germany

Mercedes Carrillo-Solano: Materials Research Department, GSI Helmholtzzentrum, Planckstr. 1, 64291 Darmstadt, Germany

Nils Ulrich and Christina Trautmann: Materials Research Department, GSI Helmholtzzentrum, Planckstr. 1, 64291 Darmstadt, Germany; and Material- und Geowissenschaften, Technische Universität Darmstadt, Alarich-Weiss-Str. 8, 64287 Darmstadt, Germany
}

Andrea Hadley and Patrick Kluth: Department of Electronic Materials Engineering, Research School of Physics and Engineering, Australian National University, Canberra ACT 2601, Australia 
Keywords: atomic layer deposition; confined geometry; hydrophilicity; mesoporous silica; nanocavity; nanoscale structuring; track-etched polymer membrane.

\section{Introduction}

Atomic layer deposition (ALD) has been reaffirmed during the last decade as a powerful technique to modify the surface of materials as various as silicon wafers, polymers, powders, or nanostructures, finding numerous applications in, e.g. electronics, surface protection, catalysis, or battery development [1-3].

In recent studies, ALD has successfully been combined with ion-track techno$\operatorname{logy}[4,5]$. For decades, ion-track membranes have been employed in applications such as water filtration, microbiology, and life sciences. The excellent control over channel size and geometry attained by selective chemical etching of ion tracks allows the design and fabrication of novel nanochannels exhibiting, e.g. ion current rectification or gating properties. Such nanochannels are of interest for many different applications including, for example, biological and chemical sensors. Ion-track nanotechnology is typically based on the irradiation of polymer foils with swift heavy ions of energy in the range of $\mathrm{MeV}-\mathrm{GeV}$ [6]. On its way through the foil, each ion creates a track, a cylindrical damaged zone of 5-10 nm in diameter. In a suitable etching solution, the damaged material along the track is selectively dissolved thus converting the track into an open nanochannel. The final diameter of the channels depends on the etching conditions (time, concentration, and temperature of the etchant) and can be adjusted between $\sim 20 \mathrm{~nm}$ up to several $\mu \mathrm{m}$. Symmetric or asymmetric etching conditions are applied to produce cylindrical or conical channels, respectively [7, 8]. Most commonly used polymers are polycarbonate (PC), polyethylene terephthalate (PET), and polyimide [9]. Nanochannels in polymer foils are very stable in aqueous solutions and can be fabricated in a reproducible manner. This makes them excellent model systems to gain a better understanding of the behavior of biological nanochannels in cell membranes in particular for studying selective transport processes of ions or molecules [10, 11].

Selective transport along solid-state nanochannels is determined by the size and geometry as well as by the surface charge of the channel. In the recent past, great efforts have been devoted to chemically modify the polymer surface and the surface charge of the nanochannels in a controlled manner. After track etching of PC or PET membranes, carboxylic groups are present at the surface, serving as basis to incorporate other functional groups both on the membrane surface and inside the nanochannels. The growth of polymer brushes and electrostatic 
layer-by-layer deposition have been demonstrated yielding highly selective and responsive nanochannels [10].

Also, physical methods such as coating by metal sputtering have been applied to modify the performance of nanochannels. In a recent example, a thin gold layer was sputtered on one side of a PC foil with conical nanochannels and used as a substrate for electrochemical polymerization of aniline. This asymmetric modification conferred $\mathrm{pH}$ and voltage responsiveness to the nanochannels [12]. The advantage of the ALD process consists in a homogeneous and conformal coating along the entire channel length [2]. The high conformity results from the self-limiting sequential ALD reactions. For metal oxide coatings, typically two precursors, one containing the metal and the other supplying oxygen are combined in ABABtype process steps $[2,3]$. For a given combination of ALD precursors, parameters such as length of the precursor pulses, purging and exposure times as well as temperature can be adjusted to yield homogeneous coatings even inside narrow, high aspect ratio pores such as track-etched channels or mesoporous silica matrices. The thickness control can be as precise as one atomic layer [4, 5, 9, 13, 14]. Combining ion-track technology with ALD provides the unique opportunity for homogeneous controlled shrinkage of the inner diameter of track-etched channels without affecting the channel geometry. Moreover, specific properties such as the surface charge, catalytic activity, corrosion resistance, and hydrophilicity can be adjusted in a controlled manner. The ALD layer also provides a well-defined inorganic layer, onto which further chemical modification steps can be applied.

This work focuses on two projects both related to ALD coating of nanostructures of confined geometries: (i) $\mathrm{SiO}_{2}, \mathrm{Al}_{2} \mathrm{O}_{3}$, and $\mathrm{TiO}_{2}$ coating of high-aspect-ratio nanochannels in track-etched PC and PET membranes, and (ii) substructuring the surface of channels in mesoporous silica by a combination of ALD and a molecular template technique as well as the application of this approach to track-etched membranes. Both track-etched membranes and mesoporous silica are employed as model systems to demonstrate the broad options of nanostructuring in confined geometries as required for nanofluidic, catalytic, and sensing applications.

\section{Experimental}

\subsection{Fabrication of track-etched membranes}

Commercial films of PET ( $36 \mu \mathrm{m}$ Hostaphan) or PC (30 $\mu \mathrm{m}$ Makrofol N) with sample diameters of $3 \mathrm{~cm}$ were irradiated with $\sim 2-\mathrm{GeV}$ Au ions at the UNILAC linear accelerator of the GSI Helmholtz Centre for Heavy Ion Research (Darmstadt, Germany). 
The irradiation was carried out in vacuum and under normal beam incidence. At such high energies, each ion creates a cylindrical track across the entire thickness of the foil. The applied fluence was $10^{9}$ ions $/ \mathrm{cm}^{2}$ resulting in randomly distributed, parallel oriented ion tracks. Before etching, the irradiated foils were exposed to UV light (wavelength 280-400 nm) for $1 \mathrm{~h}$ (PC) or $3 \mathrm{~h}$ (PET) on each side. This treatment is known to reduce the size distribution of the pores during the subsequent etching process $[8,15-17]$. Ion-track etching was performed in a $6 \mathrm{~mol} / \mathrm{L} \mathrm{NaOH}$ solution at $50{ }^{\circ} \mathrm{C}$. The etching time was adjusted to produce nanochannels with diameters between 25 and $100 \mathrm{~nm}$. The process was stopped by sequentially rinsing the etched membranes in three baths of deionized water at room temperature.

\subsection{Synthesis of silica SBA-15}

For the synthesis of silica SBA-15, $4.0 \mathrm{~g}$ of Pluronic $\mathrm{P} 123\left(\mathrm{EO}_{20} \mathrm{PO}_{70} \mathrm{EO}_{20}\right.$, BASF) were dissolved in a mixture of $120 \mathrm{~mL} 2 \mathrm{M} \mathrm{HCl}$ and $30 \mathrm{~mL}$ of deionized water in a polypropylene bottle under stirring at $35{ }^{\circ} \mathrm{C}$. Subsequently, $8.5 \mathrm{~g}$ of tetraethyl orthosilicate (TEOS, Sigma-Aldrich, $\geq 99.0 \%$ ) were added and the solution was stirred for $20 \mathrm{~h}$ at $35^{\circ} \mathrm{C}$. Then, the bottle was placed in an oven at $85^{\circ} \mathrm{C}$ for another $24 \mathrm{~h}$. The resulting suspension was filtered yielding a white powder. The product was calcined at $550{ }^{\circ} \mathrm{C}$ for $12 \mathrm{~h}[18,19]$.

\subsection{Atomic layer deposition (ALD): $\mathrm{SiO}_{2}$ coating}

ALD coatings were applied by using a stainless steel ALD reactor, which operates at a pressure of 1.3 Torr. Details of the ALD setup are described elsewhere [9]. For $\mathrm{SiO}_{2}$ coatings, several membranes were placed in the reaction chamber with a volume of $3 \mathrm{~L}$. The reactor walls were heated to $60{ }^{\circ} \mathrm{C}$. Precursors were fed into the reactor by setting the valve opening time to $0.1 \mathrm{~s}$ for both $\mathrm{SiCl}_{4}$ (Sigma-Aldrich, 99.9\%) and deionised $\mathrm{H}_{2} \mathrm{O}$. For $\mathrm{SiO}_{2}$ deposition onto PET membranes, the cyclic ABAB-type ALD process consisted of 1 min exposures to each precursor separated by 1 min intervals of $\mathrm{N}_{2}$ purging $(99.999 \%, 200 \mathrm{~mL} / \mathrm{min})$. Pyridine was used as a catalyst during both precursor exposures [4].

\subsection{Atomic layer deposition (ALD): $\mathrm{TiO}_{2}$ coating}

Initially, we could not identify covalently bound calixarene on a pure silica surface. For all further experiments, we thus coated the samples by one ALD cycle of $\mathrm{TiO}_{2}$, which facilitates covalent surface functionalization with calixarene. 
For the deposition of $\mathrm{TiO}_{2}$, a similar ALD process as described for $\mathrm{SiO}_{2}$ was applied. The reactor walls were heated to $60^{\circ} \mathrm{C}$. Up to $200 \mathrm{mg}$ of SBA-15 or one PET membrane were placed into the reaction chamber. Aiming at the deposition of a monolayer onto the surface of SBA-15, we applied three successive $\mathrm{TiCl}_{4}$ (SigmaAldrich, 99.9\%) precursor pulses followed by three $\mathrm{H}_{2} \mathrm{O}$ pulses [20]. For coating track-etched PET membranes, one pulse of each precursor was sufficient to saturate the surface with precursor. Precursors were fed into the reactor by setting the valve opening time to $0.5 \mathrm{~s}$ and $0.1 \mathrm{~s}$ for $\mathrm{TiCl}_{4}$ and $\mathrm{H}_{2} \mathrm{O}$, respectively. The cyclic ABAB-type ALD process consisted of 1 min exposures to each precursor separated by 1 min intervals of $\mathrm{N}_{2}$ purging $(99.999 \%, 200 \mathrm{~mL} / \mathrm{min})$. ALD TiO $\mathrm{Ti}_{2}$ coating of PC membranes was carried out at $\sim 95{ }^{\circ} \mathrm{C}$ using titanium isopropoxide (TTIP, SAFC Hitech) [4]. A single ALD cycle comprised (i) exposure to TTIP for $45 \mathrm{~s}$, (ii) $90 \mathrm{~s}$ of $\mathrm{N}_{2}$ purging, (iii) exposure to $\mathrm{H}_{2} \mathrm{O}$ for $45 \mathrm{~s}$, and (iv) $90 \mathrm{~s}$ of $\mathrm{N}_{2}$ purging. The flow rate during $\mathrm{N}_{2}$ purging was $50 \mathrm{~mL} / \mathrm{min}$.

\subsection{Surface modification using p-tert-butyl-calix[4]arene}

Nanostructuring of $\mathrm{TiO}_{2}$-modified SBA-15 and track-etched PET surfaces was achieved by a molecular-templated ALD approach (see Figure 6) [14, 21]. One hundred milligrams of SBA-15 or a PET membrane, in both cases ALD-coated by $\mathrm{TiO}_{2}$, were immersed into $50 \mathrm{~mL}$ of dry toluene (Sigma-Aldrich, 99.8\%) and $50 \mathrm{mg}$ p-tert-butyl-calix[4]arene (Sigma-Aldrich, 95\%). The mixture was stirred for $2 \mathrm{~h}$ at $60{ }^{\circ} \mathrm{C}$ under reflux. Modifying SBA-15 yields a yellow colored powder. Modified PET membranes remain colorless. Samples were filtered and washed with copious hot toluene and then dried at $60^{\circ} \mathrm{C}$ for $24 \mathrm{~h}$.

\subsection{Atomic layer deposition (ALD): $\mathrm{Al}_{2} \mathrm{O}_{3}$ coating}

ALD coating with $\mathrm{Al}_{2} \mathrm{O}_{3}$ was performed by applying a similar ALD process as described for $\mathrm{SiO}_{2}$ and $\mathrm{TiO}_{2}$. The reactor walls were heated to $60^{\circ} \mathrm{C}$ and a PET membrane was placed in the reaction chamber. Precursors were fed into the reactor by setting the valve opening time to $0.1 \mathrm{~s}$ for both precursors trimethylaluminium (TMA) (Sigma-Aldrich, 97\%) and $\mathrm{H}_{2} \mathrm{O}$. The cyclic ABAB-type ALD process consisted of $10 \mathrm{~s}$ exposures to each precursor separated by $30 \mathrm{~s}$ intervals of $\mathrm{N}_{2}$ purging (99.999\%, $200 \mathrm{~mL} / \mathrm{min})$.

For the preparation of nanocavities using a sacrificial nanotemplate such as p-tert-butyl-calix[4]arene, it is crucial to control the thickness of the deposited layer to prevent overcoating of the template molecules. To determine the number 
of ALD cycles necessary to generate nanocavities of well-defined depth, knowledge about the growth rate of the $\mathrm{Al}_{2} \mathrm{O}_{3}$ wall material is essential. The ALD growth rate of $\mathrm{Al}_{2} \mathrm{O}_{3}$ on planar $\mathrm{Si}(100)$ wafers was determined as $1.5 \AA$ per ALD cycle as described elsewhere [14]. Hence, as the first step, ALD coatings with five cycles of $\mathrm{Al}_{2} \mathrm{O}_{3}$ were applied to generate nanocavities with a depth of approximately $0.75 \mathrm{~nm}$. By limiting the number of ALD cycles, overcoating of the calixarene template (size: 1-2 nm) is prevented. $\mathrm{ALD} \mathrm{Al} \mathrm{O}_{3}$ coating of $\mathrm{PC}$ membranes was carried out at $\sim 95^{\circ} \mathrm{C}$ applying TMA (SAFC Hitech) and deionised $\mathrm{H}_{2} \mathrm{O}$ as precursors. The ALD cycle consisted of $45 \mathrm{~s}$ of TMA exposure followed by $90 \mathrm{~s}$ of $\mathrm{N}_{2}$ purging, $45 \mathrm{~s}$ of $\mathrm{H}_{2} \mathrm{O}$ exposure, and finally $90 \mathrm{~s}$ of $\mathrm{N}_{2}$ purging. The $\mathrm{N}_{2}$ purging flow rate was $10 \mathrm{~mL} / \mathrm{min}$.

\subsection{Ozone treatment}

Ozone treatment of the modified samples was applied in a glass vessel heated to $60{ }^{\circ} \mathrm{C}$ using an oil bath. Subsequently, the vessel was purged with $200 \mathrm{~mL} / \mathrm{min}$ ozoniferous air produced by an ozone generator (Heyl Neomeris, LAB 2B), which was fed with an airflow of $4 \mathrm{~L} / \mathrm{min}$ ( $\mathrm{p} \approx 0.2 \mathrm{bar}$ ) producing $3.5 \mathrm{mg}$ ozone/L air $(1.5 \mathrm{~g}$ ozone/h). Samples were treated for $12 \mathrm{~h}$.

\subsection{X-ray photoelectron spectroscopy (XPS)}

X-ray photoelectron spectra were aquired on a SSX 100 ESCA spectrometer (Surface Science Laboratories Inc.) employing a monochromatic Al-K $\mathrm{X}_{\alpha} \mathrm{X}$-ray source $(1486.6 \mathrm{eV})$. Spectra were recorded in the constant analyzer energy (CAE) mode at a detection angle of $36^{\circ}$. The X-ray source was operated at $9 \mathrm{kV}$ and $10 \mathrm{~mA}$, while the analysis chamber had a base pressure of $<10^{-8}$ Torr. The size of the beam spot was approximately $0.25 \mathrm{~mm}$ in diameter. Survey spectra (eight measurements) were recorded between 0 and $1100 \mathrm{eV}$ with $0.5 \mathrm{eV}$ resolution, whereas detailed spectra (30 measurements) were recorded with $0.1 \mathrm{eV}$ resolution. The $\mathrm{Si}^{4+}$ peak at $103.3 \mathrm{eV}$ was used to correct the shifts of the binding energy generated by charging effects. Data analysis included a Shirley background subtraction and a peak-fit analysis using Gaussian-Lorentzian product functions with 45\% Lorentz-

Tab. 1: Relative sensitivity factors (RSF) used for XPS analysis.

\begin{tabular}{rrrrrr}
\hline & Al 2p & C 1s & 0 1s & Si 2p & Ti 2p \\
\hline RSF & 0.537 & 1.000 & 2.930 & 0.817 & 7.810 \\
\hline
\end{tabular}


ian share. Atomic concentrations were calculated using the relative sensitivity factors (RSF) given in Table 1.

\subsection{Diffuse reflectance IR Fourier transform spectroscopy (DRIFTS)}

Diffuse reflectance infrared Fourier transform spectroscopy (DRIFTS) was performed on a Bruker Vertex 70 spectrometer equipped with a globar MIR source (silicon carbide) and a narrowband, liquid-nitrogen cooled MCT detector. Spectra were recorded between 5000 and $850 \mathrm{~cm}^{-1}$ with $0.5 \mathrm{~cm}^{-1}$ resolution (100 scans, $10 \mathrm{kHz}$ mirror velocity). The light beam was focused onto the powder sample using a Harrick Praying Mantis mirror cell. To obtain spectra of dehydrated samples, a Harrick High Temperature Reaction Chamber (HVC) was employed to heat the samples at $60^{\circ} \mathrm{C}$ for $1 \mathrm{~h}$ in an inert gas flow (Ar or $\mathrm{N}_{2}, 200 \mathrm{~mL} / \mathrm{min}$ ). Samples were then cooled to room temperature for acquisition of spectra. $\mathrm{KBr}$ was used as a reference for recording background spectra.

\subsection{Contact angle measurements}

Contact angles were measured on a OCA35 apparatus from Dataphysics Instruments $\mathrm{GmbH}$. Distilled water with a volume of $2 \mu \mathrm{L}$ was dropped onto the membrane surface at $21^{\circ} \mathrm{C}$ and $50 \%$ relative humidity of air. Besides the ALD coating, the samples were not treated otherwise prior to measurements [9].

\subsection{Small angle X-ray scattering (SAXS)}

Small angle X-ray scattering (SAXS) measurements of the nanochannels in PC and PET membranes were performed at the SAXS/WAXS beamline of the Australian Synchrotron in Melbourne, Australia. The experiments were made in transmission configuration with a photon energy of $11 \mathrm{keV}$, and a camera length of $727.9 \mathrm{~cm}$. Patterns of the scattered X-ray intensity were recorded on a 2-dimensional Pilatus $1 \mathrm{~m}$ hybrid pixel detector employing gapless mode.

To perform the SAXS measurements the nanopores were first aligned with the X-ray beam. Under these conditions, the resulting scattering pattern on the $\mathrm{X}$-ray detector consists of concentric rings caused by diffraction from the circular aperture of the nanochannels (Figure 1, left). Because of the large aspect ratio of the nanochannels, a slight tilt of the sample with respect to the X-ray beam leads to a highly anisotropic scattering pattern, consisting of two symmetric narrow 


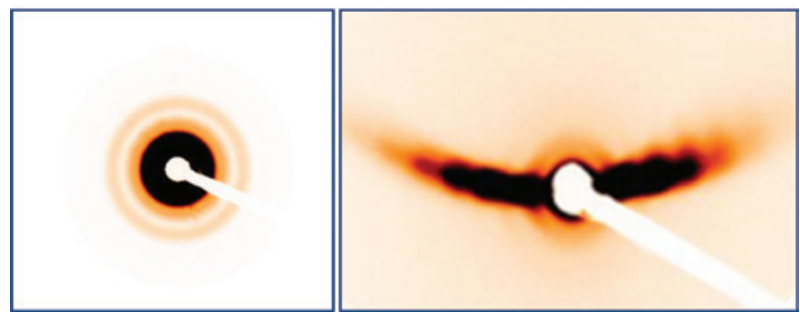

Fig. 1: SAXS images of track-etched PC membrane with nanochannels aligned (left) and tilted by $15^{\circ}$ (right) with respect to the X-ray beam.

streaks parallel to the axis of rotation (Figure 1, right) [8, 22-24]. After background subtraction, the scattered intensity, $I(\mathrm{q})$, along the streak is analyzed as a function of the scattering vector $\mathrm{q}$. To fit the data, the commercial software package IGOR was used. As form factor, we inserted a cylinder model extended by an additional cylindrical shell to account for the ALD layer deposited on the inner pore wall $[25,26]$. The analysis of the SAXS data considers parameters such as polydispersity of the cylinder radius, thickness and electron density of the coating as well as instrumental resolution and background.

\subsection{Electron microscopy}

To investigate the conformity, homogeneity, and thickness of the ALD coating inside the nanochannels, the PC and PET templates were dissolved in dichloromethane ( $>99.5 \%$, Carl Roth $\mathrm{GmbH}$ ), and a mixture of hexafluoro-2-propanol and chloroform, respectively. The released nanotubes were collected on a standard $\mathrm{Cu}$ transmission electron microscopy (TEM) grid with lacey carbon support film. The tubes were imaged using a high-resolution scanning electron microscope (JEOL JSM-7401F) equipped with a transmission electron detector (STEMin-SEM) at $20 \mathrm{kV}$ at GSI, and a TEM (JEOL ARM200CF) at (200 kV) at the Stuttgart Center for Electron Microscopy (StEM).

\section{Results and discussion}

\subsection{Coating of polymer etched ion-track membranes by ALD}

The steps employed for the fabrication of ALD coated etched ion-track membranes are illustrated in Figure 2, including (a) the irradiation of polymer 
(a)

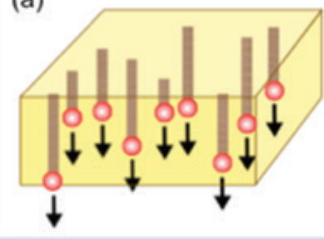

(b)

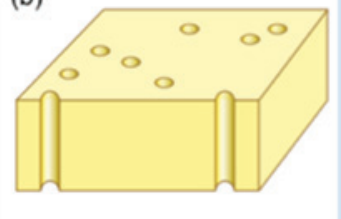

(c)

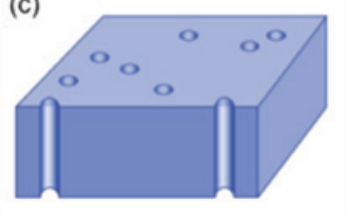

Fig. 2: Schematics of the fabrication of ALD coated membranes: (a) irradiation of a polymer foil with e.g. $2 \mathrm{GeV}$ Au ions available at the GSI accelerator facility, (b) chemical etching of ion-track membrane e.g. in $\mathrm{NaOH}$ solution to selectively dissolve the tracks and convert them into cylindrical nanochannels, (c) ALD conformal coating of porous membrane [4].

foils with swift heavy ions creating a well-defined number of ion tracks, (b) conversion of ion tracks into open nanochannels by chemical etching, and (c) conformal coating of the track-etched membrane by ALD.

Conformal ALD coating requires a layer-by-layer growth and a constant growth rate, i.e. the coating thickness should increase linearly with the number of ALD cycles. To confirm that homogeneous ALD coating is possible even inside extremely high-aspect ratio narrow nanochannels, we investigated the ALD growth mode systematically for $\mathrm{TiO}_{2}, \mathrm{Al}_{2} \mathrm{O}_{3}$, and $\mathrm{SiO}_{2}$ coatings. Three series of $\mathrm{PC}$ membranes with same initial channel diameter $(\sim 50 \mathrm{~nm})$ were coated with thin layers of various thicknesses, namely 5, 10, 15, 20, and $22 \mathrm{~nm}$ [4]. Figure $3 \mathrm{a}-\mathrm{c}$ show representative images recorded in the scanning transmission mode of a scanning electron microscope (STEM-in-SEM) of sections of the released nanotubes for three coating materials. For quantitative analysis, the inner and outer diameters were measured at various positions along 10-15 nanotubes of each sample. Both diameters are constant along the entire tube length, evidencing a conformal growth process inside the high-aspect ratio nanochannels. In all cases, the inner diameter decreases linearly with the increasing number of ALD cycles.

For each system, the mean layer thickness was determined from STEM-in-SEM images as well as from data recorded by SAXS. The obtained values are displayed in the bottom panel of Figure 3 as a function of ALD cycles. The corresponding growth rates for $\mathrm{SiO}_{2}, \mathrm{Al}_{2} \mathrm{O}_{3}$, and $\mathrm{TiO}_{2}$ are 1.8, 0.5, and $0.3 \AA$ /cycle, respectively [4].

The growth behavior of the different oxide materials depends on the specific surface species and surface chemistry involved (see Table 2). Owing to the limited thermal stability of the ion-track etched polymer membranes, the ALD conditions had to be adjusted to a low temperature process [27]. For the deposition of $\mathrm{SiO}_{2}$ onto PC membranes, we reduced the process temperature from 427 to $52^{\circ} \mathrm{C}$ [9]. As a consequence, pyridine was employed as catalyst to ensure acceptable growth rates at such low deposition temperatures [28]. In the case of $\mathrm{Al}_{2} \mathrm{O}_{3}$, Figure $3 \mathrm{f}$ 

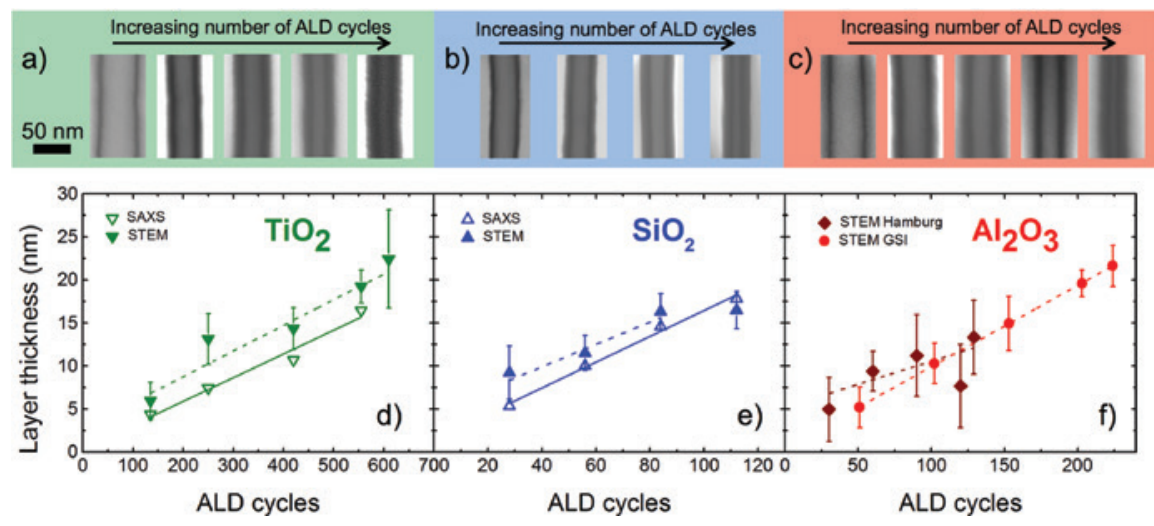

Fig. 3: Results from a systematic ALD coating series for track-etched polycarbonate membranes with $50 \mathrm{~nm}$ cylindrical nanochannels. (Top) STEM-in-SEM images of representative sections of $\mathrm{TiO}_{2}(\mathrm{a}), \mathrm{SiO}_{2}(\mathrm{~b})$, and $\mathrm{Al}_{2} \mathrm{O}_{3}$ (c) nanotubes synthesized with (from left to right) an increasing number of ALD cycles. (Bottom) Corresponding layer thicknesses as a function of ALD cycle numbers according to analysis by SAXS (open symbols) and STEM (full symbols). Solid and dashed lines are guides to the eye. Images are modified from [4].

Tab. 2: Reaction steps during ALD coating processes of $\mathrm{TiO}_{2}, \mathrm{SiO}_{2}$, and $\mathrm{Al}_{2} \mathrm{O}_{3}$.

\begin{tabular}{llll}
\hline & $\mathrm{TiO}_{2}$ & $\mathrm{SiO}_{2}$ & $\mathrm{Al}_{2} \mathrm{O}_{3}$ \\
\hline $1^{\text {st }}$ Half reaction & $\mathrm{Ti}-\mathrm{OH}{ }^{*}+\mathrm{TiO}\left(\mathrm{OCH}\left(\mathrm{CH}_{3}\right)_{2}\right)_{4} \rightarrow$ & $\mathrm{Si}-\mathrm{OH}^{*}+\mathrm{SiCl}_{4} \rightarrow$ & $\mathrm{Al}-\mathrm{OH}{ }^{*}+\mathrm{Al}\left(\mathrm{CH}_{3}\right)_{3} \rightarrow$ \\
& $\mathrm{Ti}-\mathrm{O}-\mathrm{Ti}\left(\mathrm{OCH}\left(\mathrm{CH}_{3}\right)_{2}\right)_{3}{ }^{*}+\mathrm{C}_{3} \mathrm{H}_{8} \mathrm{O}$ & $\mathrm{Si}-\mathrm{O}-\mathrm{SiCl}{ }_{3}{ }^{*}+\mathrm{HCl}$ & $\mathrm{Al}-\mathrm{O}-\mathrm{Al}\left(\mathrm{CH}_{3}\right)_{2}{ }^{*}+\mathrm{CH}_{4}$ \\
$2^{\text {nd }}$ Half reaction & $\mathrm{Ti}\left(\mathrm{OCH}\left(\mathrm{CH}_{3}\right)_{2}\right)^{*}+\mathrm{H}_{2} \mathrm{O} \rightarrow$ & $\mathrm{SiCl}+\mathrm{H}_{2} \mathrm{O} \rightarrow$ & $\mathrm{AlCH}{ }_{3}+\mathrm{H}_{2} \mathrm{O} \rightarrow$ \\
& $\mathrm{Ti}-\mathrm{OH}^{*}+\mathrm{C}_{3} \mathrm{H}_{8} \mathrm{O}$ & $\mathrm{Si}-\mathrm{OH}^{*}+\mathrm{HCl}$ & $\mathrm{Al}-\mathrm{OH}^{*}+\mathrm{CH}_{4}$ \\
Reaction & $\mathrm{TiO}\left(\mathrm{OCH}\left(\mathrm{CH}_{3}\right)_{2}\right)_{4}+2 \mathrm{H}_{2} \mathrm{O} \rightarrow$ & $\mathrm{SiCl}+2 \mathrm{H}_{2} \mathrm{O} \rightarrow$ & $2 \mathrm{Al}\left(\mathrm{CH}_{3}\right)_{3}+3 \mathrm{H}_{2} \mathrm{O} \rightarrow$ \\
& $\mathrm{TiO}_{2}+4 \mathrm{C}_{3} \mathrm{H}_{8} \mathrm{O}$ & $\mathrm{SiO}_{2}+4 \mathrm{HCl}$ & $\mathrm{Al}_{2} \mathrm{O}_{3}+6 \mathrm{CH}_{4}$ \\
\hline
\end{tabular}

During $\mathrm{SiO}_{2}$ deposition pyridine is employed as a catalyst in both half reactions. Asterisks denote reactive surface species [4].

shows the data sets from two different ALD facilities. With the first set of applied ALD parameters (reported in [4]), the obtained data (dark red rhombi) exhibit scattering indicating inhomogeneous coating probably due to diffusion limitation of the precursors during the process. The second set of data (red circles) was obtained using a Picosun R-200 system available at GSI and adjusting the exposure and purge times yielding a growth rate of $0.1 \mathrm{~nm} / \mathrm{cycle}$, in excellent agreement with the growth rate achieved on planar Si-wafers [29].

Valuable information on the thickness and inner morphology of the ALDcoated nanochannels was obtained by STEM-in-SEM. However, the preparation of the samples is tedious and time consuming, because it requires the removal 
of the polymer matrix in an organic solution. The number of analyzed channels was thus limited to typically 10-20 per sample. SAXS, on the other hand, provides information about the mean size and size distribution of a large ensemble of channels ( $10^{6}$ nanochannels) acting as scattering objects. Our samples were initially investigated at the SAXS laboratory system at the TU Darmstadt. However, due to limitations (accessible scattering vector range, long measurement times, etc.) further experiments were performed at the Australian Synchrotron in Melbourne (Australia).

The results from a series of four track-etched PC membranes, with an initial channel diameter of $28 \mathrm{~nm}$, coated with $\mathrm{SiO}_{2}$ applying 39, 48, 53, and 59 ALD cycles, are shown in Figure 4 and in Table 3. Scattering intensities $I(q)$ as

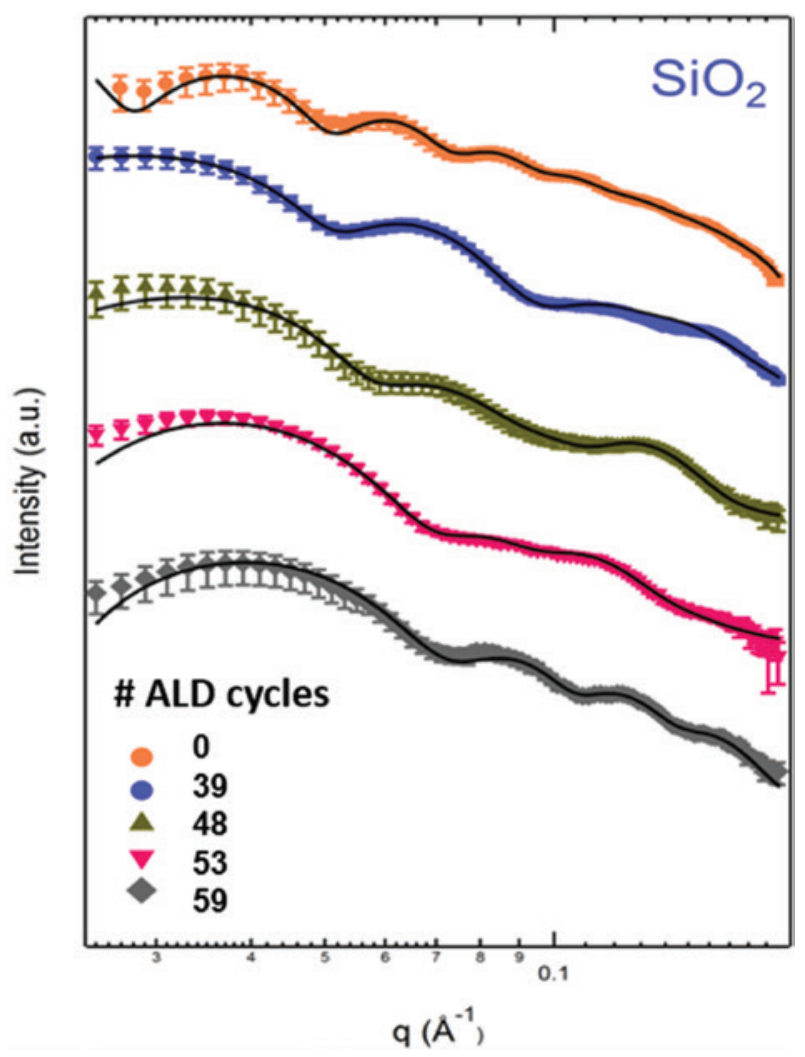

Fig. 4: Scattered intensities as a function of scattering vector measured for a 30- $\mu \mathrm{m}$ thick PC membrane with 28-nm diameter channels before and after coating with $\mathrm{SiO}_{2}$ applying different number of ALD cycles (corresponding coating thickness as deduced from SAXS are listed in Table 3). 
Tab. 3: $\mathrm{PC}$ membranes with 28-nm diameter channels before and after coating with $\mathrm{SiO}_{2}$ applying various numbers of ALD cycles.

\begin{tabular}{lrrr}
\hline $\mathrm{SiO}_{2}$ ALD cycles & $\mathbf{R}_{\text {shell }}$ & $\mathbf{R}_{\text {core }}$ & Total radius \\
\hline 0 & - & - & $14.0 \pm 0.1$ \\
39 & $5.7 \pm 0.3$ & $7.3 \pm 0.4$ & $13.0 \pm 0.4$ \\
48 & $6.8 \pm 0.3$ & $6.1 \pm 0.5$ & $12.9 \pm 0.5$ \\
53 & $8.1 \pm 0.2$ & $4.1 \pm 0.2$ & $12.2 \pm 0.2$ \\
59 & $8.8 \pm 0.5$ & $3.6 \pm 0.5$ & $12.4 \pm 0.4$ \\
\hline
\end{tabular}

Thickness of the $\mathrm{SiO}_{2}$ coating $\left(\mathrm{R}_{\text {shell }}\right)$ and radius $\left(\mathrm{R}_{\text {core }}\right)$ of open inner channel are deduced by analyzing the respective SAXS data. All values are given in $\mathrm{nm}$.

a function of the scattering vector $q$ recorded for the same uncoated reference sample at both facilities (TU Darmstadt, Australian Synchrotron) were in excellent agreement. Figure 4 displays the scattered intensity for various $\mathrm{SiO}_{2}$-coated membranes. The pronounced oscillations and the good model fits demonstrate cylindrically shaped, parallel aligned nanochannels with a narrow size distribution before and after ALD coating. With increasing number of ALD cycles, the minima and maxima of the intensity oscillations are shifted to larger $q$ values, as expected for smaller pore diameters.

Table 3 summarizes the values for the ALD layer thickness $\left(R_{\text {shell }}\right)$ and for the core radius $\left(\mathrm{R}_{\text {core }}\right)$ of the remaining open pore obtained from the fits of the SAXS data to the model. The uncertainties listed are estimated from the non-linear least squares fitting as well as from experimental uncertainties. The deduced polydispersity is well below $10 \%$; gives a measure of the deviation of the channels from perfect cylinders with uniform coatings as well as variations in the size within the ensemble of channels. The fact that there is no increase in polydispersity between coated and uncoated channels as well as the excellent fits to the model assumption confirm conformal ALD processes along the entire nanochannel length.

As expected, the ALD layer thickness shows a nearly linear increase with the number of ALD cycles, with a rate of $\sim 0.15 \mathrm{~nm} /$ cycle. This value is slightly smaller than the value obtained from the SAXS analysis of ALD coating of $50 \mathrm{~nm}$ diameter channels $(\sim 0.18 \mathrm{~nm} /$ cycle, Figure $3 \mathrm{e})$ and is possibly a result of the limited diffusion of precursor molecules inside the high-aspect ratio nanochannels. The effect could probably be avoided by further optimizing the exposure and purge times of the ALD process when coating very small nanochannels. To sum up, our SAXS analysis provides clear evidence that 25 -nm diameter nanochannels in tracketched $\mathrm{PC}$ membranes can be conformally coated by $\mathrm{SiO}_{2}-\mathrm{ALD}$ yielding channel diameters below $8 \mathrm{~nm}$. 
We also performed few tests on PET membranes, but the polydispersity of track-etched channels is evidently much larger. Figure 5a displays the scattered intensity recorded for a $36-\mu \mathrm{m}$ thick, uncoated PET membrane with a channel radius of $41.8 \pm 3.7 \mathrm{~nm}$, according to SAXS data. The intensity minima and maxima of the oscillations are much weaker indicating a less uniform channel size and, as quantitatively confirmed by SAXS analysis, providing a polydispersity of approximately $23 \%$. We ascribe this effect to the fact, that PET foils are semi-crystalline (in contrast to predominantly amorphous PC foils) resulting in a less homogeneous track etching process.

Figure 5b shows TEM images of cylindrical track-etched channels in PET with a homogenous ALD coating along the entire channel length. PET as ion-track membrane is of interest, because it is chemically more stable than PC, and in some cases more suitable for applications.

Summarizing, combining ion-track technology with ALD provides unique opportunities for the preparation of highly homogeneous and conformal coatings. The controlled shrinkage of the diameter of track-etched channels without affecting the channel geometry allows us to fabricate porous membranes with monodisperse channel diameters well below $10 \mathrm{~nm}$. The hydroxyl surface termination $(-\mathrm{OH})$, for example of $\mathrm{SiO}_{2}$ coatings, exhibits excellent hydrophilic properties facilitating various possibilities for additional surface modifications like anchoring organic molecules or depositing additional hydrophilic ALD layers with different isoelectric points $\left(\mathrm{TiO}_{2}, \mathrm{Al}_{2} \mathrm{O}_{3}\right.$, etc.). Tailoring specific surface properties is of great interest regarding catalytic activity, corrosion resistance, and adjusting the hydrophilicity in a controlled manner for studying and applying water and ion transport in confinement [9, 30, 31].
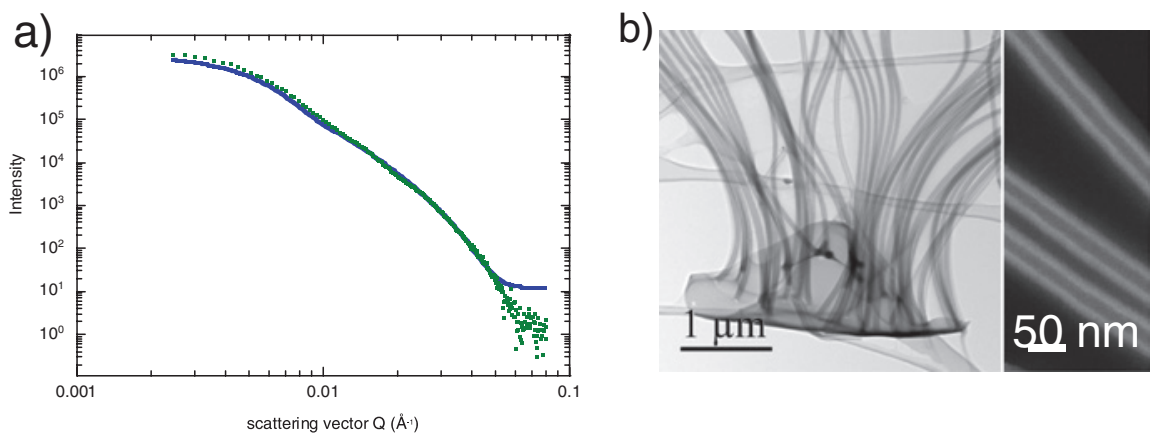

Fig. 5: (a) Scattered intensity as a function of scattering vector measured for an uncoated $36-\mu \mathrm{m}$ thick PET membrane. The channel radius is $41.8 \pm 3.7 \mathrm{~nm}$ according to SAXS analysis. (b) TEM images of a bundle of coated nanotubes obtained after dissolving the PET matrix. 


\subsection{Nanostructuring surfaces in confinement}

Conformal coating of the inner walls of nanochannels with a continuous homogeneous inorganic oxide layer is of great interest, because it allows adjusting the isoelectric point of the channel surface. Besides track-etched membranes, we were also interested in applying ALD coating to a porous inorganic material such as mesoporous silica SBA-15. Our objective was to achieve a more complex channel surface structure and an additional variation of the isoelectric point at the nanometer scale. The procedure applied is outlined in the following and shown schematically in Figure 6 [3]. We start from a hydrophilic surface of titaniacoated $\mathrm{SiO}_{2}$. The presence of the titania layer largely facilitates the attachment of template molecules [14]. As template we use large molecules such as p-tert-butylcalix[4]arene (calixarene) to generate a nanopattern of randomly distributed hydrophobic spots, that are covalently bound to the substrate surface by condensation of hydroxyl groups. This pattern forms the basis for area selective ALD, where $\mathrm{Al}_{2} \mathrm{O}_{3}$ is ALD-deposited onto the surface thereby embedding the molecular template within the $\mathrm{Al}_{2} \mathrm{O}_{3}$ layer. This process can be modified e.g. by varying the amount of calixarene grafted and the thickness of the $\mathrm{Al}_{2} \mathrm{O}_{3}$ layer.

Figure 6 illustrates how calixarene molecules may also serve as carbonaceous sacrificial template to form nanocavities [14, 21]. While removal of the calixarene template may be achieved via thermal combustion, using strong oxidants such as ozone allows to significantly reduce the combustion temperature [14, 21]. This is important when structural deformation of temperature-sensitive materials such as polymers should be avoided. The shape of the resulting nanocavities is determined by the size and geometry of the template molecules. In particular, conical cavities with diameters of 1-2 $\mathrm{nm}$ are expected when using p-tert-butylcalix[4]-arene as sacrificial template. A detailed description of the synthesis of nanocavities as well as the characterization of the intermediate steps can be found elsewhere [14, 21].

In the following, our efforts to characterize and directly visualize nanocavities on the surface of porous materials will be discussed. To this end, the template-based ALD approach using calixarene was first applied to mesoporous silica SBA-15, which offers a large specific surface area facilitating a detailed analysis of the synthesis process. Figure 7 presents high-resolution TEM images of mesoporous silica SBA-15, ALD-coated with $\mathrm{TiO}_{2}$ (one cycle) and $\mathrm{Al}_{2} \mathrm{O}_{3}$ (five cycles), with and without applying calixarene. Without calixarene, the $\mathrm{SiO}_{2}\left|\mathrm{TiO}_{2}\right| \mathrm{Al}_{2} \mathrm{O}_{3}$ nanolaminate exhibits a very smooth surface (Figure $7 \mathrm{a}$, inset). If calixarene molecules embedded within the $\mathrm{Al}_{2} \mathrm{O}_{3}$ layer are removed, nanocavities on the pore walls are created as indicated by the irregular shape of the channel walls as shown in the inset of Figure 7b [14]. 


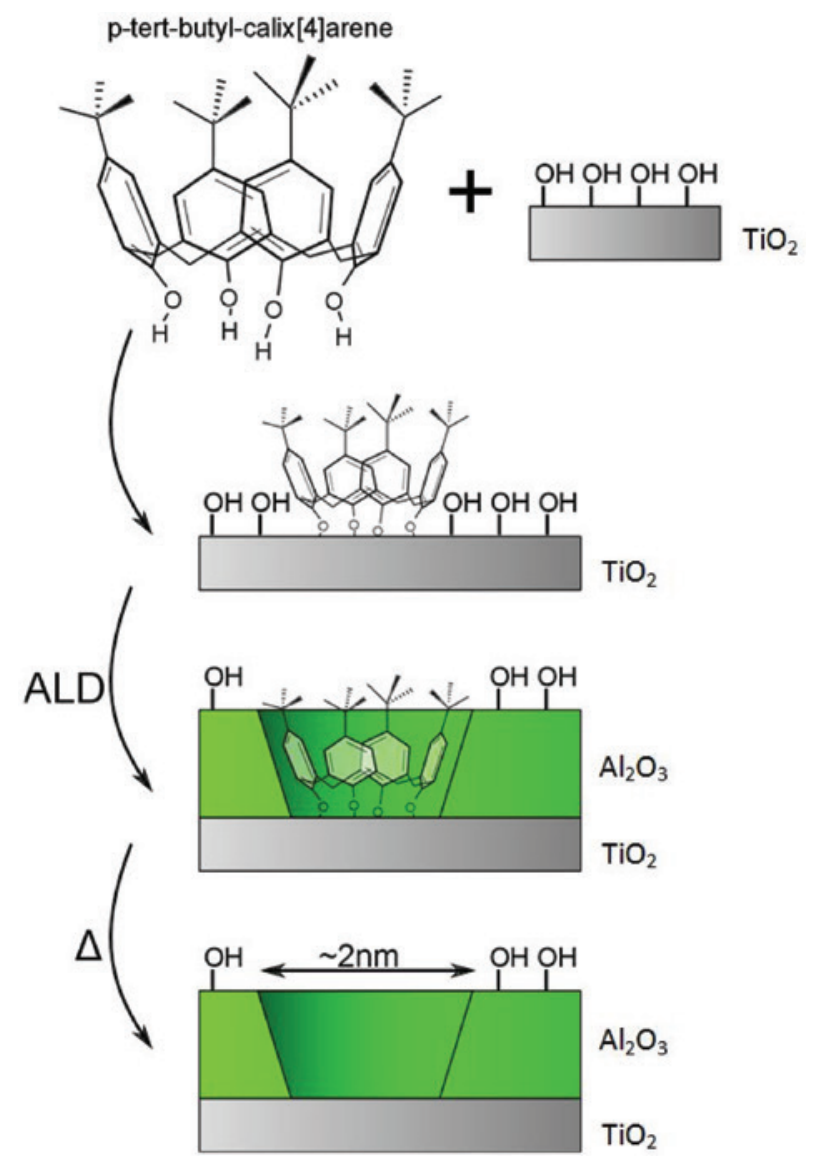

Fig. 6: Molecular-templated ALD applicable to the creation of hydrophobic nanopatterns or nanocavities. Large molecules such as p-tert-butyl-calix[4]arene (calixarene) are covalently bound to the substrate surface by condensation of hydroxyl groups (top) and act as template for the subsequent ALD coating process. Removal of the molecules results in nanocavities (bottom). Image is modified from [3].

To gain insight into the surface reactions occurring during nanocavity synthesis, IR spectroscopy was applied (Figure 8). Spectrum A of the bare calixarene shows characteristic absorption at 3140,2968 , and $2868 \mathrm{~cm}^{-1}$ with some minor features at 3055, 3023, 2941, and $2906 \mathrm{~cm}^{-1}$. The broad band centered at $3140 \mathrm{~cm}^{-1}$ is assigned to $\mathrm{OH}$ stretching modes from the crystalline state of calixarene. Absorption at $2968 \mathrm{~cm}^{-1}$ and a weak shoulder at $2941 \mathrm{~cm}^{-1}$ originate from asymmetric $\mathrm{C}-\mathrm{H}$ stretching vibrations from methyl $\left(-\mathrm{CH}_{3}\right)$ and methylene $\left(-\mathrm{CH}_{2}-\right)$ groups of the calixarene molecules, respectively. Symmetric $\mathrm{C}-\mathrm{H}$ stretching 

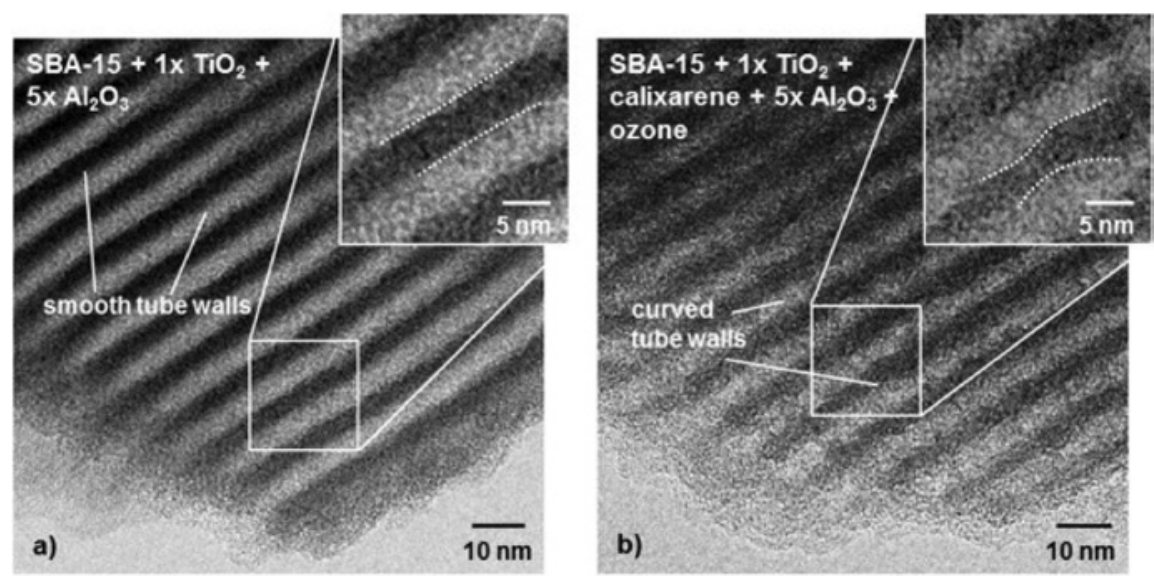

Fig. 7: High resolution TEM image of (a) $\mathrm{SBA}-15+\mathrm{TiO}_{2}$ (one cycle) $+\mathrm{Al}_{2} \mathrm{O}_{3}$ (five cycles) exhibiting smooth channel walls and (b) $\mathrm{SBA}-15+\mathrm{TiO}_{2}$ (one cycle) + calixarene $+\mathrm{Al}_{2} \mathrm{O}_{3}$ (five cycles) + ozone showing curved tube walls indicating nanocavities in the $\mathrm{Al}_{2} \mathrm{O}_{3}$ layer. The dotted lines in the insets are for better visualization of the different features of the channel walls [14].

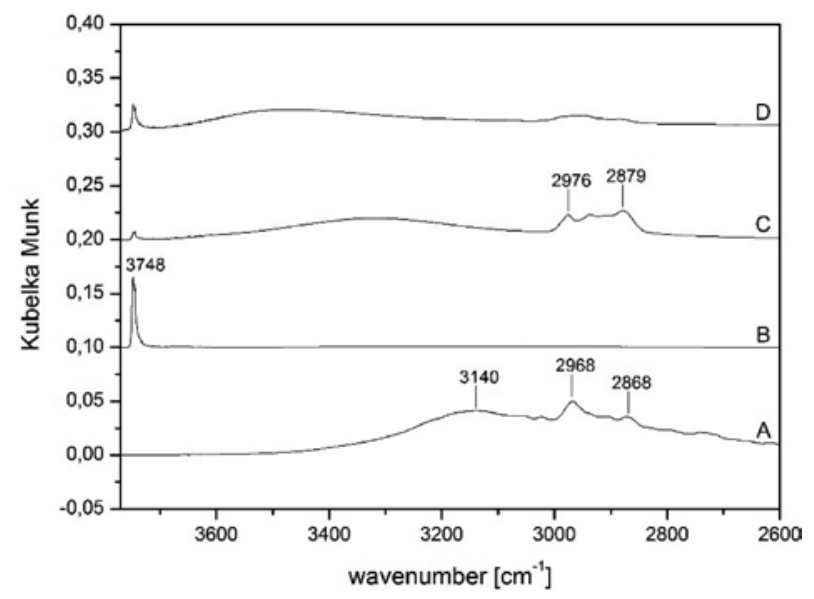

Fig. 8: IR spectra obtained during the synthesis of nanocavities on the surface of $\mathrm{TiO}_{2}$-SBA-15 at $60^{\circ} \mathrm{C}$ : (a) bare calixarene, (b) SBA- $15+1 \mathrm{xTO}_{2}$, (c) SBA- $15+1 \mathrm{x} \mathrm{TiO}_{2}+$ calixarene, (d) SBA- $15+1 \mathrm{x}$ $\mathrm{TiO}_{2}+$ calixarene removal by ozone. Spectra were normalized with respect to the Si-O-Si stretching mode at $1180 \mathrm{~cm}^{-1}$ and were offset for clarity.

vibrations from these groups are located at 2906 and $2868 \mathrm{~cm}^{-1}$. Weak bands at 3055 and $3023 \mathrm{~cm}^{-1}$ are assigned to aromatic $\mathrm{C}-\mathrm{H}$ stretching vibrations [32]. Spectrum $\mathrm{B}$ of $\mathrm{TiO}_{2}$ modified SBA-15 is characterized by residual silanol groups, which 
we attribute to (unattainable) $\mathrm{Si}-\mathrm{OH}$ preserved inside micropores due to pore blocking during ALD [14]. Subsequently, as a result of template grafting at $60{ }^{\circ} \mathrm{C}$ (spectrum C), new bands appear between 3100 and $2800 \mathrm{~cm}^{-1}$. In comparison to the spectrum of pure calixarene, the asymmetric $-\mathrm{CH}_{3}$ and the symmetric $-\mathrm{CH}_{2}$ stretching vibrations are blue-shifted by 8 and $9 \mathrm{~cm}^{-1}$ towards 2976 and $2879 \mathrm{~cm}^{-1}$, respectively. Asymmetric $-\mathrm{CH}_{2}$ - stretching vibrations are red-shifted from 2941 towards $2937 \mathrm{~cm}^{-1}$, whereas symmetric $-\mathrm{CH}_{3}$ stretching vibrations are blue-shifted from 2906 towards $2909 \mathrm{~cm}^{-1}$. These wavenumber shifts for symmetric and asymmetric stretching vibrations of methyl and methylene groups may be an indicator for the dissolution of the crystalline state of calixarene and the formation of a covalent Ti-O-C bond. Interestingly, the intensity of the band at $2976 \mathrm{~cm}^{-1}$ decreases noticeably. This behavior is initially unexpected, since the amount of methyl groups should not be reduced during calixarene grafting. However, owing to the small pore diameter of SBA-15, confinement effects may restrict some vibrations of the sterically demanding tert-butyl groups.

In summary, based on the observation of the characteristic vibrational modes of calixarene, IR spectroscopy can confirm the successful grafting of the calixarene template onto $\mathrm{TiO}_{2}-\mathrm{SBA}-15$. Additionally, the broad band centered at $3140 \mathrm{~cm}^{-1}$ vanishes completely upon grafting implying the formation of Ti-O-C covalent bonds between the calixarene template and the titania surface [14, 32]. Trace $\mathrm{D}$ represents the IR spectrum of $\mathrm{TiO}_{2}-\mathrm{SBA}-15$ + calixarene after $\mathrm{O}_{3}$ treatment at $60{ }^{\circ} \mathrm{C}$. In the region between 3100 and $2800 \mathrm{~cm}^{-1}$, only minor bands without any sharp features are detected strongly suggesting a recovery of the bare $\mathrm{TiO}_{2}$ surface of $\mathrm{TiO}_{2}$-SBA-15 as a result of template removal. The residual IR features are consistent with small amounts of carbonaceous contamination, most likely consisting of calixarene fragments.

The IR spectra recorded at $60{ }^{\circ} \mathrm{C}$ are in agreement with DFT calculations by Furer et al. and the results of our previous study at $120^{\circ} \mathrm{C}[14,32]$. Based on these findings we conclude that also a lower reaction temperature of $60{ }^{\circ} \mathrm{C}$ provides sufficient thermal energy to promote the formation of covalent Ti-O-C anchoring sites during calixarene grafting, and to decompose calixarene during $\mathrm{O}_{3}$ treatment. The decrease in reaction temperature is essential for applying the molecule-templated ALD approach to polymer membranes.

After successfully modifying the SBA-15 particles, we tested the molecular template-based nanostructuring approach on track-etched PET membranes. PC is not appropriate for nanocavity formation due to its poor resistance against toluene used as calixarene solvent during template grafting. To ensure integrity of the PET membrane during all process steps (ALD, calixarene grafting, calixarene removal), the temperature during ALD coating was reduced from 120 to 60 ${ }^{\circ} \mathrm{C}$. A simplified scheme of the overall ALD-based approach is shown in Figure 9. 


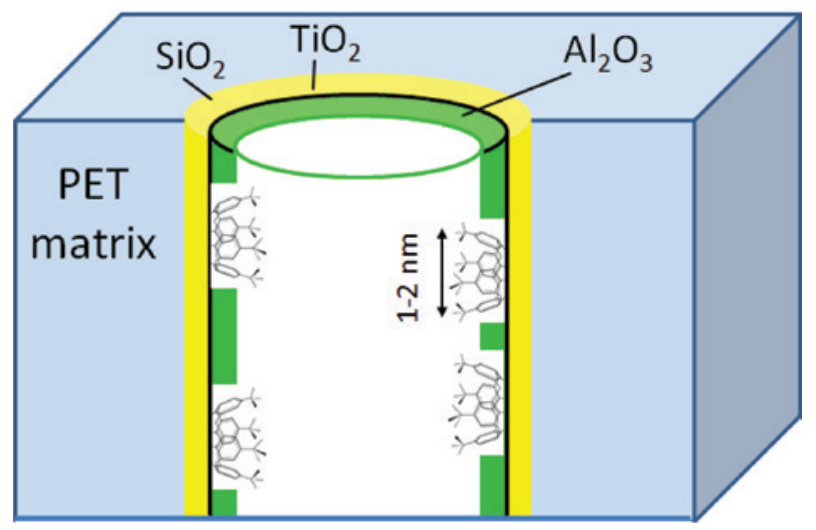

Fig. 9: Scheme (not to scale) of molecular-templated ALD applied to cylindrical track-etched nanochannels in a PET membrane, that is ALD coated with a $10-\mathrm{nm}$ layer of $\mathrm{SiO}_{2}$ ( 56 cycles, yellow) and $\mathrm{TiO}_{2}$ (one cycle, black). Subsequent to covalently binding calixarene macromolecules, the membrane is ALD coated (five cycles) with $\mathrm{Al}_{2} \mathrm{O}_{3}$. Calixarene removal by ozone treatment (not shown) leads to 1-2 $\mathrm{nm}$ wide surface nanocavities.

The ALD coatings on track-etched PET membranes produced with $\mathrm{SiCl}_{4}$ and $\mathrm{H}_{2} \mathrm{O}$ as precursors at $60{ }^{\circ} \mathrm{C}$ were characterized by X-ray photoelectron spectroscopy (XPS). Although this technique analyzes predominantly the (outer) surface of the membrane, we expect that the XPS results also represent the inner walls of the nanopores because of the conformal and homogeneous character of the ALD process. The left panel of Figure 10 shows XP spectra of the PET membrane before (a) and after ALD coating with $10 \mathrm{~nm} \mathrm{SiO}_{2}$ (b) [33]. By deconvolution of the spectra via peak-fitting, three different carbon species with binding energies of 284.7, 286.7, and $288.6 \mathrm{eV}$ can be resolved (spectrum A). They correspond to aromatic $\mathrm{sp}^{2}$ carbon (-C=C-), aliphatic $\mathrm{sp}^{3}$ carbon $\left(-\mathrm{CH}_{2}-\right)$, and carbon originating from the ester group of the PET macromolecule, respectively [34]. Upon ALD deposition of $10 \mathrm{~nm} \mathrm{SiO}{ }_{2}$, the characteristic XP signals arising from PET are completely suppressed as shown in spectrum B. The small feature observed at $285.0 \mathrm{eV}$ corresponds to minor contaminations detected by XPS. Due to the coating, the atomic concentration of carbon decreased from 72.6 (uncoated) to 10.2 at. $\%$ (coated with $10 \mathrm{~nm} \mathrm{SiO}_{2}$ ) and the respective atomic concentrations for oxygen increased from 28.4 to 57.8 at. $\%$. The amount of $\mathrm{Si}$ was determined to be 32.0 at. $-\%$ resulting in an atomic ratio $\mathrm{O}: \mathrm{Si}$ of 1.8, which is near to stoichiometry. Based on this XPS analysis we can conclude that ALD allows the growth of stoichiometric silica films on the surface of PET membranes.

Results from the XPS analysis for track-etched PET membranes ALDcoated with $\mathrm{SiO}_{2}$ and the different process steps during nanocavity formation 

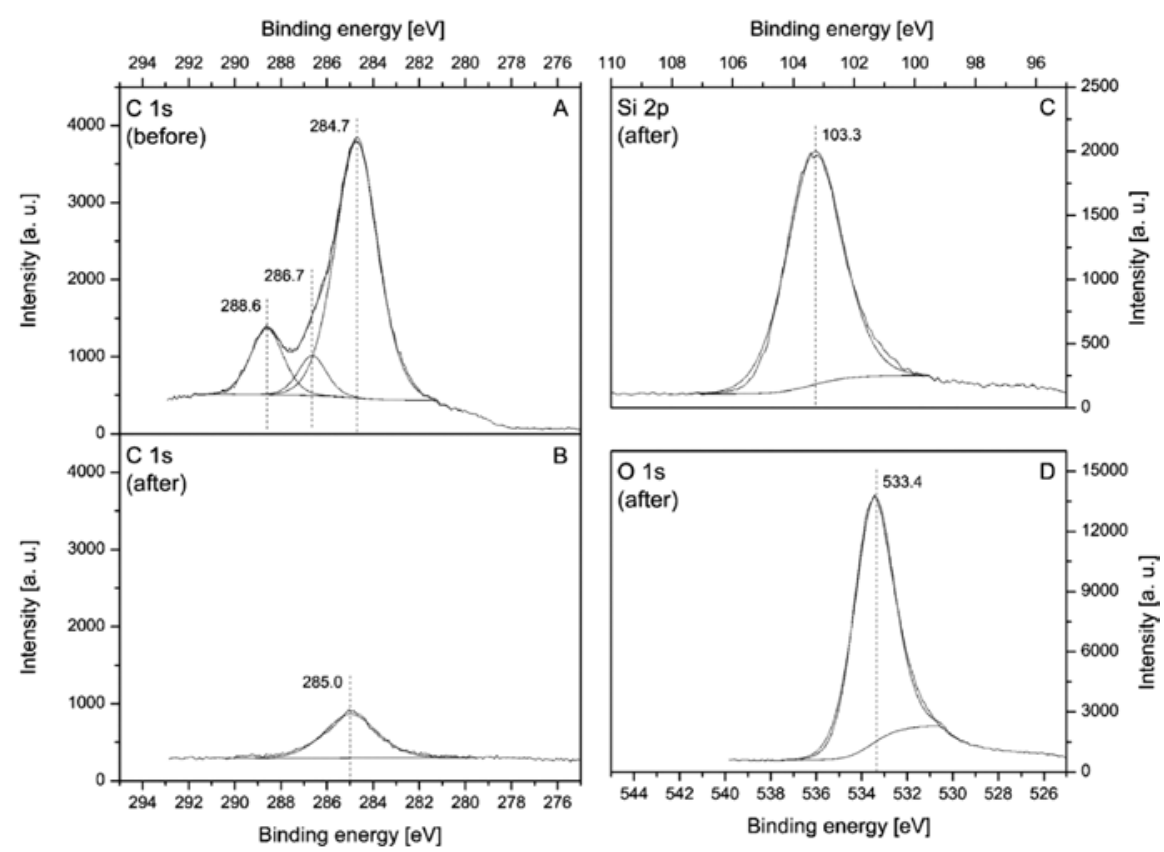

Fig. 10: Left panel: XP spectra of the $C$ 1s region obtained before (a) and after (b) ALD deposition of $10 \mathrm{~nm} \mathrm{SiO}$ on track-etched PET. Right panel: XP spectra of the Si $2 p$ (c) and 0 1s (d) regions from a sample coated with $10 \mathrm{~nm} \mathrm{SiO}{ }_{2}$. Results obtained from a peak-fit analysis are included.

by molecular-templated ALD are presented in Figure 11. The atomic concentrations based on the results of the peak-fit analysis are summarized in Table 4. The small increase in carbon content (from 10.2 at.- $\%$ to 13.6 at.-\%) when applying one ALD cycle of $\mathrm{TiO}_{2}$ to $\mathrm{SiO}_{2}$ coated samples is most likely due to contaminations detected by XPS. The only additional contribution in the 01 s region appears at $532.6 \mathrm{eV}$, consistent with the $\mathrm{O} 1 \mathrm{~s}$ emission from $\mathrm{SiO}_{2}$ [35]. The O:Si ratio was determined as 2.1, in agreement with the stoichiometry. Unsurprisingly, the low amount of $\mathrm{TiO}_{2}\left(1.4\right.$ at.-\%) overlapping with the intense $\mathrm{SiO}_{2}$ signal prevents the detection of a distinct contribution of $\mathrm{TiO}_{2}$ to the $\mathrm{O} 1 \mathrm{~s}$ region. When grafting calixarene onto the surface, the carbon content increases by 5.7 at. $\%$ to 19.3 at. $-\%$. Via peak-fitting, three features can be deconvoluted in the $\mathrm{C} 1 \mathrm{~s}$ region located at 284.6, 285.9, and $288.7 \mathrm{eV}$ (spectra b) clearly indicating the presence of new carbonaceous surface species. The appearance of a new feature at $288.7 \mathrm{eV}$ suggests the presence of carbonate $\left(\mathrm{HCO}_{3}^{-}, \mathrm{CO}_{3}^{2-}\right)$ on the substrate surface produced during heating in toluene. The observed red-shift of the peak maximum most likely originates from carbon atoms, which are part of the aromatic ring systems 

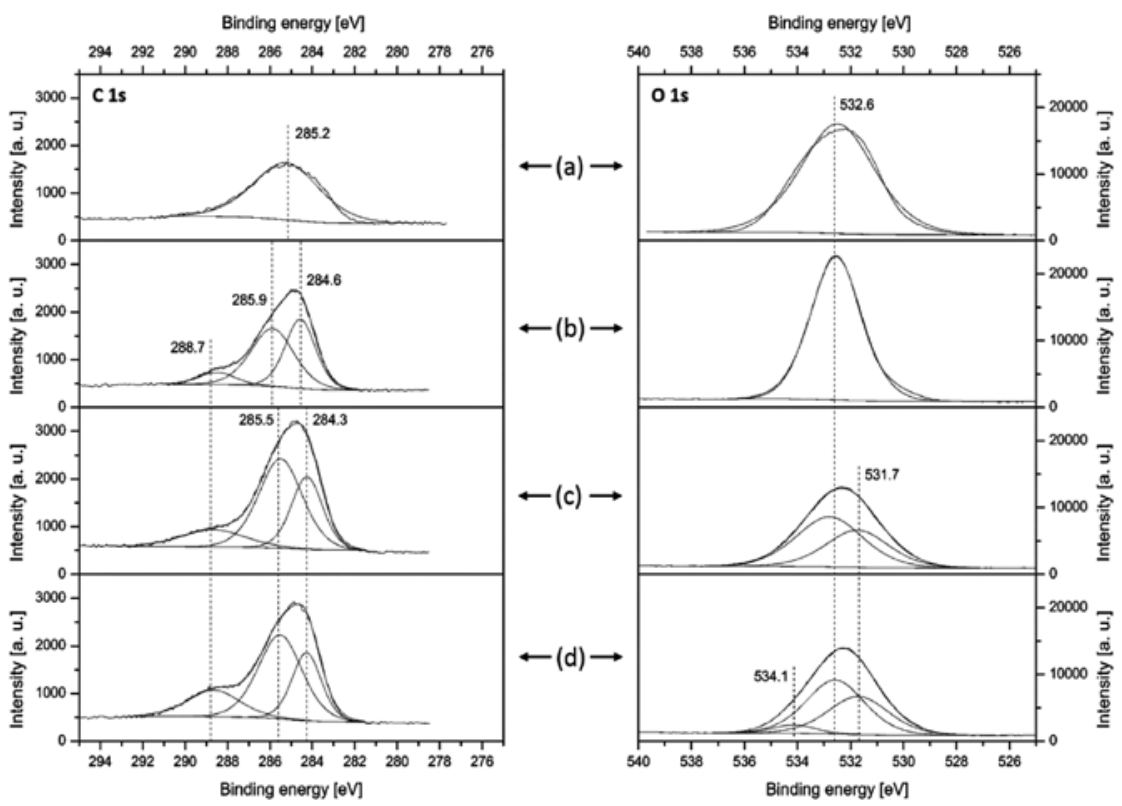

Fig. 11: XP spectra from track-etched PET surface coated with $10 \mathrm{~nm} \mathrm{SiO}$ for the $\mathrm{C} 1$ s region (left panel) and the 01 s region (right panel) during nanocavity formation by molecular-templated ALD: (a) $\mathrm{PET}+\mathrm{SiO}_{2}$ (56 cycles) $+\mathrm{TiO}_{2}$ (one cycle), (b) $\mathrm{PET}+\mathrm{SiO}_{2}\left(56\right.$ cycles) $+\mathrm{TiO}_{2}$ (one cycle) + calixarene, (c) PET $+\mathrm{SiO}_{2}$ (56 cycles) $+\mathrm{TiO}_{2}$ (one cycle) + calixarene $+\mathrm{Al}_{2} \mathrm{O}_{3}$ (five cycles), (d) $\mathrm{PET}+\mathrm{SiO}_{2}\left(56\right.$ cycles) $+\mathrm{TiO}_{2}$ (one cycle) + calixarene $+\mathrm{Al}_{2} \mathrm{O}_{3}$ (five cycles) + ozone. Results obtained from a peak-fit analysis are included.

Tab. 4: Elemental concentrations of Si, Ti, Al, C, and O (given in at.-\%) based on the XPS analysis of spectra recorded during the formation of nanocavities on the surface of ion track-etched PET coated with $10 \mathrm{~nm} \mathrm{SiO}$.

\begin{tabular}{|c|c|c|c|c|c|}
\hline & Si [at.-\%] & Ti [at.-\%] & Al [at.-\%] & C [at.-\%] & 0 [at.-\%] \\
\hline $\mathrm{PET}+56 \times \mathrm{SiO}_{2}+1 \times \mathrm{TiO}_{2}$ & 27.0 & 1.4 & - & 13.6 & 58.0 \\
\hline $\begin{array}{l}\mathrm{PET}+56 \times \mathrm{SiO}_{2}+1 \mathrm{x} \\
\mathrm{TiO}_{2}+\text { calixarene }\end{array}$ & 24.9 & 1.4 & - & 19.3 & 54.4 \\
\hline $\begin{array}{l}\mathrm{PET}+56 \times \mathrm{SiO}_{2}+1 \mathrm{x} \mathrm{TiO}_{2} \\
+ \text { calixarene }+5 \mathrm{xl}_{2} \mathrm{O}_{3}\end{array}$ & 13.8 & 0.6 & 9.8 & 30.1 & 45.7 \\
\hline $\begin{array}{l}\mathrm{PET}+56 \times \mathrm{SiO}_{2}+1 \times \mathrm{TiO}_{2} \\
+ \text { calixarene }+5 \mathrm{xl}_{2} \mathrm{O}_{3}+\text { ozone }\end{array}$ & 11.6 & 0.6 & 8.4 & 30.5 & 48.9 \\
\hline
\end{tabular}

of the calixarene molecule [35]. Also, in the 01 s region only one contribution assigned to $\mathrm{SiO}_{2}$ with a near to stoichiometry $\mathrm{O}: \mathrm{Si}$ ratio of 2.2 can be resolved. Interestingly, by subsequent application of five ALD cycles of $\mathrm{Al}_{2} \mathrm{O}_{3}$ (spectra c), 
the carbon content increases by 10.8 at.-\% predominantly caused by the feature at $285.5 \mathrm{eV}$. Additionally, the two features at 284.6 and $285.9 \mathrm{eV}$ are slightly redshifted towards 284.3 and $285.5 \mathrm{eV}$, respectively. Such an increase of the surface carbon content may result from a transmetalation during $\mathrm{Al}_{2} \mathrm{O}_{3}$ ALD when using highly reactive TMA as a precursor. TMA is capable of splitting Ti-O-Ti bonds and thus creating $\mathrm{Ti}-\mathrm{CH}_{3}$ species, which are then incorporated and preserved within the ALD layer. A similar behavior was reported by Lakomaa et al. [36] for the ALD coating of $\mathrm{Al}_{2} \mathrm{O}_{3}$ on $\mathrm{SiO}_{2}$ performing ${ }^{29} \mathrm{Si}$ cross polarization/magic angle spinning nuclear magnetic resonance (CP MAS NMR) measurements for characterization. The corresponding $\mathrm{O}$ 1s spectrum exhibits two contributions at 531.7 and $532.6 \mathrm{eV}$ assigned to $\mathrm{Al}_{2} \mathrm{O}_{3}$ and $\mathrm{SiO}_{2}$, respectively [35]. Atomic ratios for O:Si and O:Al are determined as 1.9 each. Subsequent to thermal ozone treatment at $60{ }^{\circ} \mathrm{C}$ (spectra d), no further shifts are observed in the $\mathrm{C} 1$ s region. The intensity of the feature at $288.7 \mathrm{eV}$ increases, while the two features at 284.3 and $285.5 \mathrm{eV}$ slightly decrease in intensity. The amount of carbon detected by XPS remains stable ( -30 at.- $\%)$. In this context, the FTIR spectra obtained for SBA-15 point to extensive decomposition of the calixarene molecules (Figure 8). Consistent with the IR results, the intensity increase of the $\mathrm{C} 1 \mathrm{~s}$ signal at $288.7 \mathrm{eV}$ (spectra d) indicates the formation of partially oxidized fragments such as carboxyl species remaining on the surface during ozone treatment. This interpretation of the calixarene decomposition process is supported by our previous study on the characterization of nanocavity formation on SBA-15 at $120{ }^{\circ} \mathrm{C}$ [14]. Beside the $\mathrm{O}$ 1s contributions arising from $\mathrm{SiO}_{2}$ and $\mathrm{Al}_{2} \mathrm{O}_{3}$, an additional contribution at $534.1 \mathrm{eV}$ can be deconvoluted via peak-fit analysis suggesting the presence of water. The presence of water might be expected owing to the more hydrophilic surface after calixarene decomposition
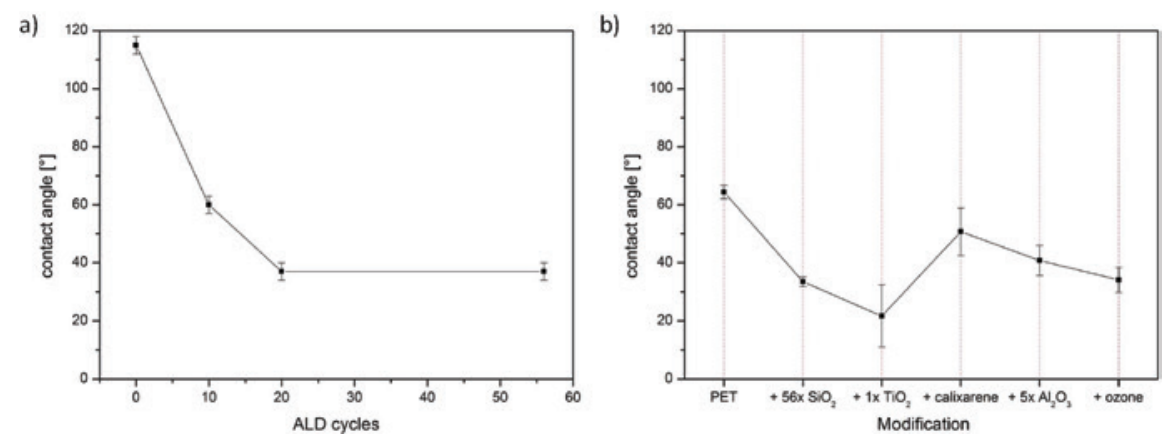

Fig. 12: Contact angle measurements for ALD coated track-etch polymer membranes: (a) $\mathrm{SiO}_{2}$ coated PC membrane as a function of ALD cycles, [9] (b) PET membrane before and after each process step applied for the formation of nanocavities. 
[14] and is confirmed by the appearance of a broad IR band between 3400 and $3600 \mathrm{~cm}^{-1}$ (Figure 8, spectrum D) characteristic for $\mathrm{OH}$-vibrations of $\mathrm{H}$-bonded water [37].

To demonstrate the potential of the applied method for tailoring the hydrophilic/hydrophobic properties of ALD-coated polymer surfaces, we performed contact angle measurements. Upon ALD coating of PC membranes, the initially hydrophobic surface becomes more and more hydrophilic with increasing layer thicknesses of $\mathrm{SiO}_{2}$ (Figure 12a) [9]. A similar behavior is observed for ALD coating of PET membranes, which change after the deposition of $10 \mathrm{~nm} \mathrm{SiO}_{2}$ from the initial contact angle $64^{\circ} \pm 2^{\circ}$ to $34^{\circ} \pm 2^{\circ}$. The addition of one $\mathrm{TiO}_{2}$ layer causes the contact angle to further decrease to $22^{\circ} \pm 11^{\circ}$. While for untreated PET and PET +56 ALD cycles of $\mathrm{SiO}_{2}$ the standard deviation of the contact angle is quite small $\left( \pm 2^{\circ}\right)$, the contact angle after adding one additional cycle of $\mathrm{TiO}_{2}$ does not change very much, but has a standard deviation of $\pm 11^{\circ}$. This is in agreement with literature reporting similar hydroxyl surface densities of 4.6 and $4.8 \mathrm{OH} / \mathrm{nm}^{2}$ for fully hydrated silica and titania surfaces, respectively [38]. Interestingly, calixarene grafting leads to a strong increase of the contact angle up to $51^{\circ} \pm 8.2^{\circ}$. This behavior implies the hydrophobic tert-butyl groups of calixarene to be aligned upwards, consistent with the results of the IR and XPS analysis as well as the previously proposed adsorption mechanism outlined above (Figure 6). Subsequent to calixarene attachment, the hydrophilicity is re-increased by the deposition of $\mathrm{a} \sim 0.75 \mathrm{~nm}$ thick $\mathrm{Al}_{2} \mathrm{O}_{3}$ layer (five ALD cycles) yielding a contact angle of $41^{\circ} \pm 5.2^{\circ}$. Since the calixarene molecules are embedded within this $\mathrm{Al}_{2} \mathrm{O}_{3}$ layer, the increase in hydrophilicity can be rationalized by the presence of the hydrophilic metal oxide surface. Finally, as expected, removal of calixarene by thermal ozone treatment further reduces the contact angle to $34^{\circ} \pm 4.3^{\circ}$. The surface hydrophilicity is therefore restored to a level comparable to $\mathrm{SiO}_{2}$ coated PET (contact angle $\sim 34^{\circ}$ ).

\section{Conclusions}

Nanoscale structuring in confined geometries using ALD was illustrated for PC and PET track-etched membranes as well as for mesoporous silica SBA-15. The developed template-based bottom-up approach is based on surface decoration of nanopores with macromolecules and yields surface nanocavities. In particular, the use of p-tert-butyl-calix[4]arene as covalently bound sacrificial template molecules was investigated defining the dimension of the resulting nanocavities to 1-2 $\mathrm{nm}$. Special interest for creating such reduced pore diameters using ALD and decorating the surface of pore walls with hydrophobic template molecules 
arises from studying water and ion transport in confinement. To this end, the surface charge may be controlled by the choice of the coating material.

In a first step of our study, the suitability of the ALD process to conformally coat high aspect ratio nanochannels in track-etched polymer membranes was developed. Reducing the process temperature of the specific coating process to $60{ }^{\circ} \mathrm{C}$ avoids damage to the polymer matrix. We demonstrate that ALD allows conformal coating of $30 \mu \mathrm{m}$ long channels with initial diameters as small as $28 \mathrm{~nm}$. Homogeneous $\mathrm{SiO}_{2}, \mathrm{TiO}_{2}$ and $\mathrm{Al}_{2} \mathrm{O}_{3}$ layers of thickness between 5 and $20 \mathrm{~nm}$ were obtained. SAXS measurements provide evidence that coated nanochannels, particularly in PC membranes, are characterized by a very small pore size distribution.

In the second part of the study, we focused on using macromolecules as nano-templates during ALD coating. Mesoporous silica SBA-15 was decorated by calixarene molecules. Owing to its amorphous silica pore walls and its large specific surface area, SBA-15 provides excellent qualities as a model support material. We found that grafting of calixarene onto SBA-15 largely benefits from an ALD coating of $\mathrm{TiO}_{2}$. The later removal of calixarene is efficiently obtained by a thermal ozone treatment. For surface analysis, IR spectroscopy has proven to be most useful, since calixarene exhibits characteristic absorption bands. The principle of calixarene decoration of SBA-15 was successfully transferred to nanochannels in track-etched PET membranes as supported by XP spectroscopy. As shown by contact angle measurements, the wettability behavior of PET during the different stages of nanocavity formation changed remarkably. The originally hydrophobic PET turned hydrophilic upon deposition of $\mathrm{SiO}_{2}$ and $\mathrm{TiO}_{2}$ owing to the newly created surface hydroxyl groups. Subsequent grafting of hydrophobic calixarene molecules onto the surface, leads to a pronounced increase of the contact angle. This illustrates that the outlined approach allows controlling the hydrophilic properties in the confined geometries of porous materials.

Acknowledgements: The authors would like to thank Karl Kopp for technical support, Maximilian Nau for his assistance with contact angle measurements, Prof. Dr. K. Nielsch and his group (Universität Hamburg) for ALD test coatings, and Dr. Wilfried Sigle (MPI for Solid State Research) for TEM imaging. Financial support by the Deutsche Forschungsgemeinschaft (DFG-FOR1583) is gratefully acknowledged. Part of this research was undertaken on the SAXS/ WAXS beamline at the Australian Synchrotron. P.K. acknowledges the Australian Research Council for financial support from the Future Fellowship scheme (FT120100289). 


\section{References}

1. R. W. Johnson, A. Hultqvist, S. F. Bent, Mater. Today 17 (2014) 236.

2. S. M. George, Chem. Rev. 110 (2010) 111.

3. N. Sobel, C. Hess, Angew. Chem. Int. Ed. 54 (2015) 15014.

4. A. Spende, N. Sobel, M. Lukas, R. Zierold, J. C. Riedl, L. Gura, I. Schubert, J. M. Moreno, K. Nielsch, B. Stühn, C. Hess, C. Trautmann, M. E. Toimil-Molares, Nanotechnol. 26 (2015) 335301.

5. C. Wang, Q. Fu, X. Wang, D. Kong, Q. Sheng, Y. Wang, Q. Chen, J. Xue, Anal. Chem. 87 (2015) 8227.

6. C. Trautmann, Ion Beams in Nanoscience and Technology, in: R. Hellborg, H. J. Whitlow, Y. Zhang (Eds.), Springer, Berlin Heidelberg (2009).

7. M. E. Toimil-Molares, Beilstein J. Nanotechnol. 3 (2012) 860.

8. T. W. Cornelius, B. Schiedt, D. Severin, G. Pépy, P. Y. Apel, C. Boesecke, C. Trautmann, Nanotechnol. 21 (2010) 155702.

9. N. Sobel, C. Hess, M. Lukas, A. Spende, B. Stühn, M. E. Toimil-Molares, C. Trautmann, Beilstein J. Nanotechnol. 6 (2015) 472.

10. G. Perez-Mitta, A. G. Albesa, C. Trautmann, M. E. Toimil-Molares, O. Azzaroni, Chem. Sci. 8 (2017) 890.

11. Z. S. Siwy, S. Howorka, Chem. Soc. Rev. 39 (2010) 1115.

12. G. Pérez-Mitta, W. A. Marmisollé, C. Trautmann, M. E. Toimil-Molares, O. Azzaroni, J. Am. Chem. Soc. 137 (2015) 15382.

13. J. W. Elam, J. A. Libera, T. H. Huynh, H. Feng, M. J. Pellin, J. Phys. Chem. C 114 (2010) 17286.

14. P. Ruff, S. Lauterbach, H. J. Kleebe, C. Hess, Microp. Mesop. Mater. 235 (2016) 160.

15. P. Apel, I. V. Blonskaya, S. N. Dmitriev, O. R. Orelovitch, A. Presz, B. A. Saertowska, Nanotechnol. 18 (2007) 305302.

16. E. Ferain, R. Legras, Nucl. Instr. Meth. Phys. Res. B 84 (1994) 331.

17. Z. Zhu, Y. Maekawa, Q. Liu, M. Yoshida, Nucl. Instr. Meth. Phys. Res. B 236 (2005) 61.

18. C. Hess, J. D. Hoefelmeyer, T. Don Tilley, J. Phys. Chem. B 108 (2004) 9703.

19. Z. Luan, E. M. Maes, P. A. W. van der Heide, D. Zhao, R. S. Czernuszewicz, L. Kevan, Chem. Mater. 11 (1999) 3680.

20. IR experiments on SBA-15 performed prior and after coating with three $\mathrm{TiCl}_{4}$ half cycles followed by three $\mathrm{H}_{2} \mathrm{O}$ half cycles showed a $55 \%$ decrease in silanol intensity. Thus, based on these results one may estimate that about $55 \%$ of the surface was covered with titania.

21. C. P. Canlas, J. Lu, N. A. Ray, N. A. Grosso-Giordano, S. Lee, J. W. Elam, R. E. Winans, R. P. Van Duyne, P. C. Stair, J. M. Notestein, Nat. Chem. 4 (2012) 1030.

22. G. Pépy, P. Boesecke, A. Kuklin, E. Manceau, B. Schiedt, Z. Siwy, M. Toulemonde, C. Trautmann, J. Appl. Crystal. 40 (2007) 388.

23. B. Kuttich, M. Engel, C. Trautmann, B. Stühn, Appl. Phys. A 114 (2014) 387.

24. T. Bierschenk, B. Afra, M. D. Rodriguez, R. Giulian, C. Trautmann, S. Mudie, M. C. Ridgway, P. Kluth, J. Appl. Cryst. 40 (2007) 388.

25. M. Engel, B. Stühn, J. J. Schneider, T. Cornelius, M. Naumann, Appl. Phys. A 97 (2009) 99.

26. P. Kluth, C. S. Schnohr, O. H. Pakarinen, F. Djurabekova, D. J. Sprouster, R. Giulian, M. C. Ridgway, A. P. Byrne, C. Trautmann, D. J. Cookson, K. Nordlund, M. Toulemonde, Phys. Rev. Lett. 101 (2008) 175503.

27. O. Sneh, M. L. Wise, A. W. Ott, L. A. Okada, S. M. George, Surf. Sci. 334 (1995) 135. 
28. Y. Du, X. Du, S. M. George, Thin Solid Films 491 (2005) 43.

29. A. Spende, Surface Modification of Etched Ion-Track Polymer Membranes by Atomic Layer Deposition, Doctoral Tesis, Technische Universität Darmstadt (2016). Available online: http://tuprints.ulb.tu-darmstadt.de/5613/1/PhDThesis_Anne\%20Spende.pdf.

30. R. B. Schoch, J. Han, P. Renaud, Rev. Mod. Phys. 80 (2008) 839.

31. W. Sparreboom, A. van den Berg, J. C. Eijkel, Nat. Nanotechnol. 4 (2009) 713.

32. V. L. Furer, E. I. Borisoglebskaya, V. V. Zverev, V. I. Kovalenko, Spectrochim. Acta A 62 (2005) 483.

33. For deposition of a $10-\mathrm{nm} \mathrm{SiO}$ layer, 56 cycles were applied. The ALD growth rate of $1.8 \AA$ / cycle for $\mathrm{SiO}_{2}$ films was measured via SAXS. Refer to reference [4] for details.

34. G. Beamson, D. Briggs, High Resolution XPS of Organic Polymers: The Scienta ESCA300 Database, John Wiley \& Sons, Chichester (1992).

35. J. F. Moulder, W. F. Stickle, P. E. Sobol, K. D. Bomben, Handbook of X-ray Photoelectron Spectroscopy, Perkin-Elmer Corporation Physical Electronics Division, Eden Prairie (1992).

36. E. L. Lakomaa, A. Root, T. Suntola, Appl. Surf. Sci. 107 (1996) 107.

37. T. M. Costa, M. R. Gallas, E. V. Benvenutti, J. A. da Jornada, J. Phys. Chem. B 103 (1999) 4278.

38. R. Mueller, H. K. Kammler, K. Wegner, S. E. Pratsinis, Langmuir 19 (2003) 160. 